\title{
JARDINES DEL ALMA. HACIA UNA TEOLOGÍA COMPARADA DE LA ALHAMBRA Y EL CASTILLO INTERIOR
}

\author{
GARDENS OF THE SOUL. TOWARDS \\ A COMPARATIVE THEOLOGY OF THE \\ ALHAMBRA AND THE INTERIOR CASTLE
}

María M. Carrión

\section{Resumen}

Esta lectura comparada de los conjuntos monumentales de la Alhambra en Granada y el Castillo interior de Teresa de Jesús es una rêverie teológica y literaria que propone entender estos dos textos como jardines del alma, es decir, como espacios donde florece un sentido espiritual y un pensamiento religioso que trasciende toda una serie de fronteras. Estos dos textos son tan distintos que se podría decir que no se prestan a una lectura comparada, mucho menos una con un centro referencial teológico. En suma, se puede entender que esta empresa no sea aconsejable, y que estos dos textos se deban dejar separados motu proprio, como si fueran agua y aceite. Sin subestimar estas diferencias, y sin ánimo de menoscabar las tradiciones religiosas y literarias que los han canonizado por separado, este ensayo contempla la posibilidad de una teología comparada con estos dos textos, la cual plantea una clara relación con lo divino y que entiende lo sublime en la diferencia de estos espacios. Con esta lectura se podrá apreciar un amor sin fronteras por la naturaleza y, sobre todo, por el agua y sus propiedades divinas de abundancia y prodigalidad, que se pueden leer como medio y canal de fe y esperanza. Este es amor protegido por un amplio paisaje de flores, frutas, árboles y demás flora natural y artística dentro y fuera de los palacios nazaríes de la Alhambra y del tratado místico de Teresa de Jesús. Este amor por las maravillas de los jardines, por la belleza más grande, por la bendición del agua, y por Dios-Allāh mueve la teología comparada que motiva a escribir estas páginas.

Palabras claves: La Alhambra; Teresa de Jesús; Castillo interior; Teología comparada; Arquitectura andalusí; Agua; Jardines. 


\begin{abstract}
This comparative reading of the monumental oeuvres of the Alhambra and The Interior Castle by Teresa de Jesús is a theological and literary reverie that depicts these two texts as gardens of the soul, that is to say, as spaces where spiritual awareness and religious thought flourish and transcend borders. The profound differences that separate these two texts render them virtually unfit for a proper comparison, especially one in which the referential framework is theological. At first glance. These two texts may best be read individually, water and oil. Without aiming to undermine the distinctions that set them apart, or the religious and literary traditions that have canonized them separately, this article rehearses a comparative theology built upon these two texts, one that posits a clear relationship with the divine and understands the sublime in the gap between these spaces.

With this reading, it will be possible to witness a boundless love for nature, and above all, for water and its divine properties of abundance and bounteousness, which can be read as a medium and channel of faith and hope. This love is protected by a vast landscape of flowers, fruits, trees, and other forms of natural and artistic flora in and out of the Nasrid palaces of the Alhambra, as well as inside and out of the mystical treatise by Teresa de Jesús. This love for the marvels of the gardens, for the supreme beauty, for the blessing of water, and for God-Allāh moves the comparative theology that prompts the writing of these pages.
\end{abstract}

Keywords: Alhambra; Teresa de Jesús; Interior Castle; Comparative Theology; Andalusi architecture; Water; Gardens.

No hay en este jardín (raw ) maravillas (bad $i$ ) que Dios no quiso que semejantes hallaran la Belleza (al-usn)? Ibn Zamrak, "Bendito sea Aquel"1

Para Alex Mexi y Violeta Ruiz Espigares, por esos palacios

1 Citado en Leer La Alhambra. Guía visual del monumento a través de sus inscripciones. ed. José Miguel Puerta Vílchez (Granada: Edilux. Patronato de La Alhambra y Generalife, 2011), 169. Todos los poemas de Ibn Zamrak, Ibn al-Khațib e Ibn al-Ŷayyāb que aparecen en estas páginas se encuentran representados de manera epigráfica en la Alhambra provienen de la "Guía visual del monumento a través de sus inscripciones" compilada y editada por Puerta Vílchez; en paréntesis, el número de página donde aparece citado el correspondiente poema. A menos que se indique lo contrario, todas las traducciones son de la autora. Le agradezco a Manuela Ceballos y a Gloria Maité Hernández por su inspiración y tesón de lectura de textos místicos y teologías comparadas. 
Esta lectura comparada de los conjuntos monumentales de la Alhambra en Granada y el Castillo interior de Teresa de Jesús es una rêverie teológica y literaria que propone entender estos dos textos como jardines del alma. ${ }^{2}$ Como revela el poema epigráfico de Ibn Zamrak, 'este jardín' o raw del Patio de los Leones en la Alhambra aloja maravillas en las que se conjugan el grado máximo de Belleza (alusn) con la voluntad de Dios-Allāh, de tal manera que ese lugar viabiliza el acercamiento a lo divino. Siguiendo esta clave de escritura el presente ensayo plantea que, al leer con buena voluntad estos espacios, tanto los lectores como las comunidades a las que ellos pertenecen pueden quizás llegar a aprehender y experimentar la presencia divina. La Alhambra de Granada y el Castillo interior son dos textos tan distintos que se podría decir que no se

2 La Alhambra aquí se refiere al conjunto monumental de palacios y jardines nazaríes en la ciudad de Granada, España, declarado Patrimonio de la Humanidad por la UNESCO en 1984. Aunque las fechas de construcción del conjunto más ampliamente entendido se extienden del siglo nueve al dieciséis, este ensayo se concentrará en los palacios nazaríes de Comares y Los Leones, así como en el Partal y el Generalife; las fechas de construcción de estas cuatro áreas de la Alhambra son 1238-1391. El Castillo interior, por su parte, es el penúltimo libro que, en 1577, poco antes de morir, compone Teresa de Jesús -también conocida como Santa Teresa, Teresa de Ávila y otros nombres-. El Libro de la vida, compuesto un poco más de una década antes, y el Castillo interior son las dos obras más reconocidas de esta autora, y este último es uno de los tratados de mística más importantes de España, con el Cántico espiritual de San Juan de la Cruz. prestan a una lectura comparada, mucho menos una con un centro referencial teológico. Razones no sobran para ello, pues las barreras que se erigen entre estos dos espacios son tan numerosas como poderosas: entre otras, los siglos que separan sus épocas de composición; las diferencias que median la arquitectura y la literatura; los espacios y roles de hombres y mujeres, que no se deben mezclar; las funciones de habitación, por un lado, de sultanes o califas con sus séquitos cortesanos y, por otro, las de monjas y sus comunidades conventuales; los castillos y palacios, que no son lo mismo ni se escriben igual; y por supuesto, el Islam y el Catolicismo, sedes de dogmas y espacios de fe que nunca se deben confundir.

En suma, se puede entender que esta empresa no sea aconsejable, y que estos dos textos se deban dejar separados motu proprio, como si fueran agua y aceite. Sin subestimar estas diferencias, y sin ánimo de menoscabar las tradiciones religiosas y literarias que los han canonizado por separado, este ensayo contempla la posibilidad de una teología comparada con estos dos textos, la cual plantea una clara relación con lo divino y que entiende lo sublime en la diferencia de estos espacios. Con esta lectura se podrá apreciar un amor sin fronteras por la naturaleza y, sobre todo, por el agua y sus propiedades divinas de abundancia y prodigalidad, amor protegido por un amplio 
paisaje de flores, frutas, árboles y demás flora natural y artística dentro y fuera de los palacios nazaríes de la Alhambra y del gran tratado místico de Teresa de Jesús. Este amor por las maravillas de los jardines, por la belleza más grande, por la bendición del agua, y por Dios (Allāh) mueve la teología comparada que motiva a escribir estas páginas.

El objetivo de esta rêverie es explorar los aspectos materiales y simbólicos que hermanan la representación natural en ambos textos, y proponer una lectura de ambos como jardines del alma, es decir, como espacios donde florece un sentido espiritual y un pensamiento religioso que trasciende toda una serie de fronteras. ${ }^{3}$ En breve, al comparar estos dos textos se podrá apreciar cómo las muchas maneras en las que representan el agua, su presencia y su flujo, así como su reverberación en los jardines y espacios de amplitud humana pueden ser medio y canal de fe y esperanza. A pesar de los ámbitos de violencia, estrechez y amenaza en los que se produjeron estos textos, y de que estos llevaron prácticamente a su ruina y hasta a su desaparición, desprecio o relego al olvido, ambos pervivieron y hoy día se mantienen en las retinas, en

3 En mis anteriores ensayos, "Amor a Dios, por amor al arte," "Primero huerto" y "Scent of a Mystic Woman" he planteado tres acercamientos a la capacidad polisémica y transconfesional de la idea y arquitectura del jardín en el Libro de la vida y en el Castillo interior de Teresa de Jesús. (Ver la bibliografía). la mente y en el corazón de millones de lectores quienes han practicado, cada uno en su propio universo, una rêverie que contiene alguno de los principios de lectura que aquí se proponen. Con esto no se pretende enaltecer estos textos, ni establecer que uno es más importante que el otro, ni cuestionar ni confirmar sus canonizaciones religiosas, artísticas o literarias; por el contrario, estas letras invitan a los lectores a visitar estos espacios físicos y letrados y a meditar sobre cómo el saber de uno y otro subraya la revelación de la presencia divina en el flujo del agua que alimenta los jardines del alma.

\section{Discurso del método de la rêverie, o el jardín de senderos que se trifulcan}

Parece que digo algún disparate; porque si este castillo es el ánima claro está que no hay para qué entrar, pues se es él mismo; como parecería desatino decir a uno que entrase en una pieza estando ya dentro. Mas habéis de entender que va mucho de estar a estar; que hay muchas almas que se están en la ronda del castillo que es adonde están los que le guardan, y que no se les da nada de entrar dentro ni saben qué hay en aquel tan precioso lugar ni quién está dentro ni aun qué piezas tiene. Ya habréis oído en algunos libros de oración aconsejar al alma que entre dentro de sí; pues esto mismo es.

Teresa de Jesús, Castillo interior (1 M 1,5) 
Tanto la Alhambra como el Castillo interior revelan una voluntad incesante de escribir sobre el encuentro con lo divino. En ese sentido son textos místicos, pues en toda su extensión material contienen un empeño de narrar un suceso inefable. Ahora bien, estas narrativas no se limitan meramente a describir estos eventos de encuentro; por tanto, el método de esta lectura teológica comparada tampoco debe ceñirse a ello. Por el contrario, aunque la escritura en las paredes y suelos de la Alhambra y el Castillo interior está inspirada por el anhelo de dicha unión, a una misma vez también revela unas barreras substanciosas que impiden dicho encuentro. Estas se transforman en una serie de contradicciones características de estos espacios, obstáculos por medio de los cuales los lectores pueden apreciar, paradójicamente, la liberación que supone el circular sin límites en su seno, y la importancia espiritual que representa dicha liberación.

Ya se han mencionado los filtros de periodización, métodos y estilos artísticos como obstáculos de una lectura comparada a los que se le suman los de religión y género sexual; estas barreras se han venido a codificar en un manejo institucional de estos dos espacios que se justifica en aras de unas relaciones de nacionalismo. Este manejo ha llevado a una compleja dinámica histórico-social que D. Fairchild Ruggles entiende como una 'ideologización del pasado,' producida en la Alhambra por las tensas relaciones entre Catolicismo e Islam: "En España, los agentes a cargo del rehacer (o "restaurar") los monumentos islámicos han sido cristianos europeos, que vale tanto como decir que no tienen ninguna auto-identificación con el pasado musulmán y árabe que la Alhambra conmemora". ${ }^{4}$ En un nivel de base, la Nación, España es, al menos en teoría y en un nivel jurídico-económico propietaria de estos espacios, ente responsable de la protección y bienestar del conjunto monumental; en un universo paralelo, aunque diferente por ser obra literaria, esa misma Nación cultiva y maneja la protección y bienestar del Castillo interior, sin haber atendido tradicionalmente a la presencia de otras tradiciones religiosas que en su fábrica textual se encuentran. ${ }^{5}$

En la Alhambra, la imagen de una posible comunión de tradiciones ha venido a constituir una memoria social, la cual José Antonio González Alcantud considera signo crítico para poder entender la 'propiedad e identidad de la Alhambra.' En el transcurso de un proyecto antropológico de memorial oral del monumento que se

4 D. Fairchild Ruggles. "Ideologizing the Past." International Journal of Middle Eastern Studies 45 (2013): 576

5 Luce López-Baralt ha estudiado extensamente 'las huellas del Islam' en la obra de San Juan de la Cruz, y ha explorado la traza del símbolo de los siete castillos o moradas concéntricas de Abū al-Hasan al-Nūrī de Bagdad en el Castillo interior. 
extendió cinco años, González Alcantud pudo entrever la complejidad de este asunto:

a la pregunta de a quién pertenece la Alhambra, interrogante central del conflicto político, social y cultural, nuestros entrevistados suelen responder de la siguiente manera: si son políticos contestan que 'a la Humanidad,' si son gentes corrientes, que 'a los granadinos.' Si se introduce el tema árabe o moro entre los entrevistados para generarles dudas, vuelven a reafirmar los primeros que 'a la Humanidad,' valor que disimula cualquier querella, y que los sitúa en el ámbito de la globalización, apreciada por todos como inevitable. ${ }^{6}$

La tensión de lo global con lo local se negocia por el tamiz de la $\mathrm{Na}$ ción y su juego con la globalización; ahora bien, si se entiende la caracterización que hace Benedict Anderson de la Nación como una comunidad política imaginada, "como algo intrínsecamente limitado y soberano," se hace posible el argumento de la teología comparada del Islam y el Catolicismo de la Alhambra y el Castillo interior. ${ }^{7}$ Anderson subraya la importancia de entender que esta entidad es imaginada, "porque los miembros incluso de las

6 José Antonio González Alcantud (dir.), Sandra Rojo Flores y José Muñoz, La Alhambra, mito y vida. 1930-1990. Tientos de memoria oral y antropología de un Patrimonio de la Humanidad (Granada: Universidad de Granada, 2016), 443.

7 Benedict Anderson, Imagined Communities. Reflections on the Origin and Spread of Nationalism (New York: Verso, 2006), 6. más pequeñas naciones nunca conocerán a la mayoría de sus compañeros, ni se reunirán con ellos, incluso ni sabrán nada sobre ellos, pero con todo eso en la mente de cada uno de ellos vive la imagen de su comunión". 8

En su estudio más abiertamente antropológico, González Alcantud nota una clave importante para entender la Alhambra como jardín del alma: "desmenuzando esas primeras sensaciones un aspecto que detectan varios de nuestros entrevistados es el denso silencio de la Alhambra, solo interrumpido por los sonidos ambientales. Un paisaje sonoro que invita a la contemplación". ${ }^{9}$ Este paisaje sonoro, y no las barreras que pueden erigir los muros, el tiempo o las instituciones, es el lugar donde el presente ensayo encuentra ese espacio de contemplación, de comunión, no solo en la Alhambra, sino también en el Castillo interior. Dicho espacio, ampliamente representado en ambos textos, se da en una poderosa incertidumbre cultural, una indecidibilidad de significación y representación, y en un territorio común que Homi Bhabha plantea que se ha dejado de notar en muchos debates contemporáneos sobre la cultura. ${ }^{10} \mathrm{~A}$

\footnotetext{
8 Ibíd.

9 González Alcantud (dir.), Rojo Flores y Muñoz, La Alhambra, mito y vida, 137.

10 Homi Bhabha, "Cultural Diversity and Cultural Differences," en The Post-Colonial Studies Reader. Edited by B. Ashcroft, G. Griffiths y H. Tiffin (New York: Routledge, 2006), 206.
} 
diferencia de esas retóricas divisivas de la 'diversidad cultural,' el invocar 'diferencias culturales' según Bhabha lleva a "problematizar la división de pasado y presente, de tradición y modernidad, tanto en el nivel de representación cultural como en su manera autoritaria de hablar". ${ }^{11}$ Esto, a su vez, cuestiona de raíz toda una serie de narrativas fijas sobre la Alhambra y el Castillo interior que se han perpetuado y repetido sin cesar, y que no toman en cuenta los habitantes de sus espacios. Al proponer una teología comparada de un texto islámico y uno católico, los cuales representan dos caras ideologizadas del pasado español, invito a los lectores de este ensayo a relativizar, si no a descartar, la unidad o totalidad cultural de estos espacios, para leer la escritura profunda que en ellos reside. Al ocupar esto, que Bhabha denomina el tercer espacio, se posibilita la lectura de las maravillas inscritas en la lengua y en la actuación que producen estos textos, una relación subconsciente (entre los textos y entre los lectores y sus contextos) que según Bhabha abre la puerta para que

11 Ibíd., 207.
Imagen 1. Vista de la Alcazaba desde la Torre de la Vela. La Alhambra, Granada

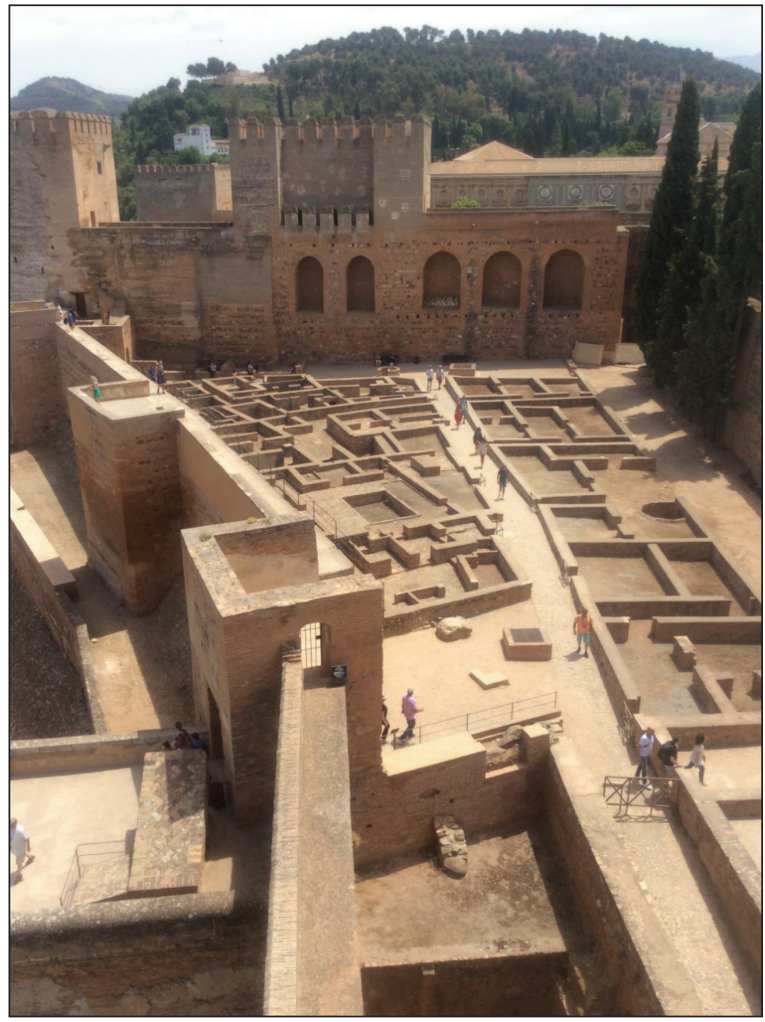

Fotografía: María M. Carrión.

se produzca "una ambivalencia en el acto de interpretación". ${ }^{12}$ Con estas claves se podrán entender los muros de separación que aparecen en los textos, no como signos de diversificación, sino de hibridez.

En ambos textos ya se prefiguran dichas barreras. Como nota Puerta Vílchez, la propia incepción de la Alhambra revela un mundo bélico y de

12 Ibíd., 208. 
fronteras divisorias: en $1238 \mathrm{MuHam}$ mad I, Ibn Nașr ibn al-AḤmar, al-Ghālib bi-Llah (el Vencedor con la ayuda de Dios) traslada la sede del gobierno del Albaicín a la colina de la Sabika, rehace la Alcazaba, construye torres y murallas, y establece la Acequia Real; así también adopta el lema dinástico (Imagen 1). Será su tercer hijo varón, MuHammad II, quien ampliará los amurallamientos de la Sabika e iniciará la edificación del Generalife. Incluso el período de esplendor arquitectónico de la Alhambra (1333-1391), con las obras de diseño y construcción dirigidas por Yūsuf I y MuḤammad V que produjeron espacios extraordinarios como el oratorio del Partal, la torre y el salón de Comares (1333-1354), el nuevo Mexuar con qubba y solio, el Patio de Arrayanes, la fachada de Comares y al-Riyād al-Sa'īd o Jardín Feliz, también conocido como el Palacio de los Leones (1362-1391), revelan numerosos deseos y actos de separar, de establecer una vida de muros y barreras que les recuerdan a todos los súbditos nazaríes los mundos jerárquicos en los que habitaban. La fuerza de gravedad que pesa en la cima de este monte sublime, así como el control de acceso a los espacios dentro y fuera de las estructuras de las distintas estancias de los palacios nazaríes de la Alhambra, mantienen viva una gestalt de compartimientos que en una dinámica paradoja funden y confunden el compartir con el separar.
El Castillo interior participa en estos senderos que se trifulcan. A vista de pájaro, sus lectores pueden apreciar que la estructura de este castillo es una de división de moradas: "Pues consideremos que este castillo tiene -como he dicho- muchas moradas, unas en lo alto, otras abajo, otras a los lados; y en el centro y mitad de todas estas tiene la más principal, que es adonde pasan las cosas de mucho secreto entre Dios y el alma". ${ }^{13}$ La unión con la divinidad, en otras palabras, no se puede pensar y experimentar como un trayecto lineal sin obstáculos, sino que aparece dibujado en el Castillo como un laberinto que alberga un posible avance hacia otros estados, pero que como trayecto vital reconoce lapsos y recaídas. ${ }^{14}$

El epígrafe arriba citado de Tereza de Jesús les ofrece a sus lectores una solución para imaginar, sentir, aprehender y experimentar este camino hacia el encuentro con lo divino. Tanto en la Alhambra como en el Castillo interior esta solución se manifiesta en el ubicuo flujo del agua. Y es aquí, en estos senderos que se trifulcan y en la presencia del agua por todas partes, donde aparece una teología comparada. Una lectura de la teología de estas dos religiones (y propongo que otras, además del Islam y el Catolicismo)

13 M1 C1 N3.

14 Catherine Swietlicki analiza la iconografía fálica y unidireccional con la que se ha asociado el Castillo interior. 
avanzaría, como plantea Francis Clooney, hacia un discernimiento y evaluación del significado religioso de otras tradiciones según se corresponden, o no, con la religión de uno; este método "puede ser muy detallado en cuanto a las sutilezas de la tradición propia, pero más a menudo permanece en unos términos generales en lo tocante a las tradiciones sobre las que se está hablando". ${ }^{15}$ Así pues, cabría preguntar qué significan los jardines y el agua en las tradiciones islámicas (para entender el significado teológico de la Alhambra) y en las tradiciones cristianas, y más específicamente católicas en el Castillo. En este marco de lectura de la teología de estas dos religiones se encuentran vastos cuerpos bibliográficos sobre estos dos textos, que remiten a los lectores a diversas consideraciones sobre estos asuntos; ahora bien, ese no es el objetivo de la presente lectura, pues lo que se analiza aquí es una teología comparada, y no un análisis teológico diverso de estas dos religiones.

Para precisar esta herramienta fundamental en el método-rêverie del presente ensayo, Clooney ofrece dos claves principales: por una parte, la teología comparada es "una modalidad de indagación que toca una amplia gama de asuntos con toda la

15 Francis Clooney, Comparative Theology: Deep Learning Across Religious Borders (Chichester, West Sussex: Wiley-Blackwell, 2010), 10. fuerza intelectual, pero que normalmente lo hace dentro de los parámetros de un compromiso con una comunidad religiosa, de un respeto hacia sus escrituras sagradas, a sus tradiciones, y prácticas, y de una voluntad de afirmar las verdades y valores de dicha tradición”. ${ }^{16}$ Así pues, el ánimo de leer literalmente las barreras y de separar estas aguas no informa esta lectura de la Alhambra como castillo interior, o del tratado místico como partícipe de ciertas premisas de los espacios nazaríes.

La segunda clave de Clooney, que remite a un tiempo en el que la teología no se teorizaba ni se practicaba a fuerza de divorcios y dogmas de exclusión, entra plenamente en el Tercer Espacio de Bhabha: "En un nivel más profundo, y para, más sencillamente, hacer eco de una antigua caracterización de la teología, [la teología comparada] es fe que busca comprensión, una práctica en la que las tres palabras -la fe, la búsqueda, la meta intelectual- tienen su fuerza plena y permanecen en una tensión productiva la una para con la otra". ${ }^{17}$ En virtud de este acto de búsqueda intelectual y de fe se puede lograr aprehender no solo la propia tradición (a la cual no se renuncia ni se niega), sino una o más tradiciones diferentes a la que uno identifica como

16 Ibíd., 9.

17 Bhabha, "Cultural Diversity and Cultural Differences," 9. 
Imagen 2. Manuscrito del Castillo interior [en el centro, sobre la maqueta metálica del castillo, entre varias reliquias de la Santa]. Sevilla: Convento

Carmelita de San José del Carmen

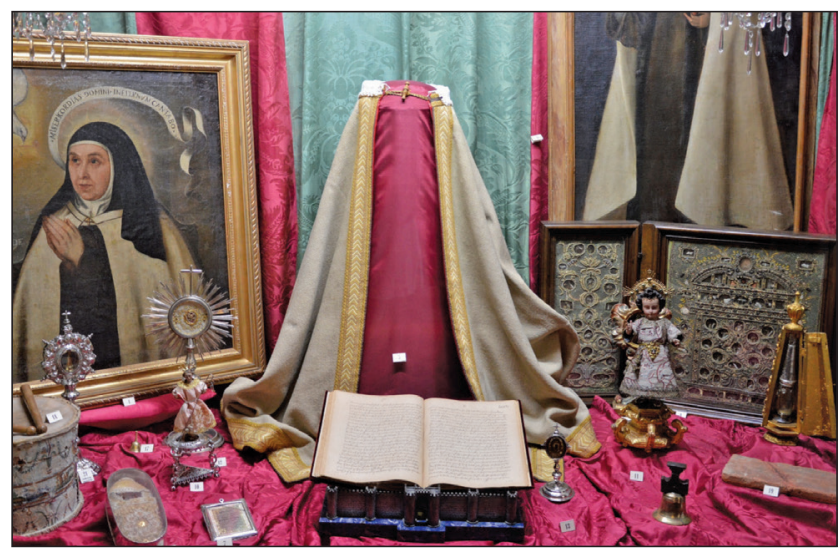

Fotografía: José Manuel Angulo Maldonado. suya. ${ }^{18}$ Por último, Clooney nos ayuda a zanjar la barrera de los métodos y plataformas textuales al proponer que la reflexión teológica se puede dar "en la oración o en la liturgia, en música o en el arte" (Imagen 2). ${ }^{19}$

La representación de la naturaleza y, en particular, la vegetación y el agua es motivo artístico que hace posible esta rêverie teológica de la Alhambra y el Castillo interior. La correspondencia que dicho ámbito natural encuentra con casi todas las paredes de los palacios, castillos, fuentes, jardines y laberintos de estos dos textos es palpable; sin embargo, las lecturas que de ellos se han hecho no siempre revelan la riqueza de voces que le dan

18 Ibíd, 10.

19 Clooney, Comparative Theology, 57. vida a esta conjunción natural, artística y cultural. ${ }^{20}$ Las estructuras arquitectónicas, como ya se ha dicho, prefiguraron desde su momento de producción las fronteras limitativas que se han usado como rasero para interpretar estas edificaciones y sus múltiples significados; así, por ejemplo, el que estos jardines y palacios se consideren meros residuos de un pasado islámico o católico extraño uno del otro, extranjero, vacío, o que se entiendan primordialmente como monumentos catalogados, mantenidos y controlados como patrimonio nacional del Estado español, o que se los reduzca a un espacio frío de objeto monumental de turismo o de lectura obligada. Para Laura Eggleton este vacío se ha producido porque el ornamento palacial se ha desgajado de su relación con la estructura y con la función de ciertos espacios, y como resultado, el significado de la ornamentación en el marco del programa arquitectónico de la Alhambra como

20 El manual de guía y lectura del Monumento de la Alhambra a través de sus inscripciones publicado por Puerta Vílchez representa una contribución significativa a cambiar este cuadro. El manual toma en cuenta elementos arquitectónicos, poéticos, históricos y caligráficos, y ofrece una ayuda indispensable para los lectores de este texto. 
conjunto se ha visto rebajado a una mera rélica, a un fetiche, un souvenir escultural o una memoria de un objeto entero, lo cual no es. ${ }^{21}$

Esta rêverie, con la que se espera conectar estos dos textos para reanimar sus diferentes significados, sigue en cierto modo el legado de Jules Goury y Owen Jones, quienes movilizaron lecturas críticas de la Alhambra relacionadas con lo que Walter Benjamin caracterizara como la obra de arte en la era de la reproducción mecánica. Así, este trabajo propone un esbozo de lectura del 'aura' de la Alhambra y el Castillo interior, método en el que se dirime una ciencia y un arte de la teología del ornamento y la función alhambreños y castelares. La ornamentación que caracterizan estos dos textos, aunque de claros tintes geométricos o matemáticos, es corolario de una geometría natural, y como tal invoca otras fronteras naturales, intelectuales, espirituales y estéticas de estas edificaciones. Al cruzar estas fronteras aquí se hará hincapié en una que aglutina significados de distintos referentes: la de la Alhambra como castillo interior y el castillo interior alhambrado, alegoría de lectura que propone leer

21 Laura Eve Eggleton, "Re-envisioning the Alhambra: Readings of architecture and ornament from medieval to modern" ( $\mathrm{PhD}$ diss. University of Leeds, 2011). También Dodds (citada anteriormente) y Cynthia Robinson, quien se plantea la posibilidad de "Arturo en la Alhambra," proponen una mirada a lo gótico-medieval cristiano como inspiración de este castillo interior. estos espacios teológicos como alma y corazón, como signo místico, como evento inefable. Líneas, proporciones, materiales, composiciones, colores, distancias, sonidos, sensaciones; elementos de constitución de los jardines y el agua que adornan las paredes del Palacio de Comares o el Palacio de los Leones, ecos cantarinos de los propios elementos de los jardines en las distintas moradas del tratado místico. Enredados en estas naturalezas arquitectónicas los lectores conscientes de estos jardines pueden hallar la fe no solo en las suras del Corán o las invocaciones de Dios que profiere de Jesús, sino también en los versos de Ibn al-Khațîb y su pupilo Ibn Zamrak, en la Belleza / alusn de estos espacios, y en formación de un universo ornamental y vegetal con resonancias tanto islámicas como cristianas y andalusíes.

La solución de lectura, que no se debe confundir con una propuesta de única o definitiva lectura de ninguno de estos dos textos, sino como un eco del flujo del agua para pasar a otro espacio de habitación en unión, pasa ahora a visitar los jardines y el agua, que fluye de unas estancias palaciales y de unas moradas a otras. La Alhambra les muestra a los lectores del Castillo cómo mantener flujo y pulso de agua, corazón que palpita y mueve la sangre en el cuerpo pensante y sensible, y el Castillo les muestra a los lectores de la Alhambra cómo fluir por estancias llenas de 
oscuridad y de obstáculos, primeras moradas que sugieren un ascenso paralelo a la fuerza de gravedad en la Alhambra, y alcanzar espacios sublimes tanto en un nivel estético como espiritual.

Jardines dentro, jardines fuera: ornamentación, naturaleza y fe

Jamás vimos alcázar más excelso, de contornos más claros y espaciosos. Jamás vimos jardín más floreciente, de cosecha más dulce y más aroma.

Ibn Zamrak, "Poema de la Sala de Dos Hermanas"

En una lectura literal, a primera vista parecería que los únicos jardines de la Alhambra se hallan afuera, y que la poesía y la religión que justifican el sello 'islámico' del monumento se hallan dentro, en un plano referencial separado de los jardines. En el Castillo interior, el término jardín solo aparece una vez, al final del tratado, textura que contrasta abiertamente con la presencia tangible del jardín y sus sinónimos en el Libro de la vida: jardín, huerto, huerta y vergel. Ahora bien, la presente lectura propone considerar lo que Ruggles ha entendido como un sistema de profundas redes de conexión entre estructura, ornamento e inscripciones, en el cual los múltiples miradores de los palacios nazaríes se deben entender como un complejo sistema de vistas y miradas que no solo abren el palacio a las vistas exteriores, sino que además, exigen de sus espectadores y habitantes un "auténtico acto de visión". ${ }^{22}$ Este sistema óptico, arquitectónico y jardinero se constituye por la correspondencia entre el diseño de las ventanas a modo de marco perforado, a través del cual, en palabras de Ruggles "se ha establecido una relación sujeto-objeto, y en el cual el regente que observaba el paisaje a su alrededor se erigía como el comandante de la vista o, de hecho, en su creador". ${ }^{23}$ En Lindaraxa, para ser más precisos, Ruggles concluye que la decoración (compuesta de vegetación geométrica y ornamental) sirve para "desmaterializar la barrera entre regente y dominio" en virtud del juego de luz y sombra que se da en el yeso esculpido. ${ }^{24}$

En un intento de analizar más en detalle este sistema de representación arquitectónica y paisajística de la Alhambra, Cynthia Robinson considera lo que ella llama el "ornamento marginal," herramienta hermenéutica con la cual se puede entender que los elementos arquitectónicos y ornamentales de estos palacios nazaríes poseen propiedades miméticas que se reflejan en los versos andalusíes plasmados por todos los patios y salones de los palacios nazaríes. Según Robinson, la yuxtaposición de verso, estructura y ornamento vinieron a representar jardines

22 D. Fairchild Ruggles, "The Eye of Sovereignty: Poetry and Vision in the Alhambra's Lindaraja Mirador," Gesta 36 (1997) 2: 183.

23 Ibíd.

24 Ibíd., 180. 
en la escritura literaria y filosófica de la época en la que se escribieron, y esta correspondencia hay que explorarla y contemplarla de manera mucho más completa y sofisticada de lo que se ha hecho hasta ahora. Estas herramientas de interpretación son absolutamente necesarias porque la Alhambra se ha mantenido y conservado y cuidado, pero se la ha vaciado de sentido y de experiencias vitales entre las que los jardines al revés que aquí propongo ocupan un lugar clave.

Así, por ejemplo, la unidad ornamental llamada en español ataurique (derivada del árabe al-tawr q), que significa flora, hojas, o follaje, que en el período nazarí establece un puente con el arte Almorávide y Almohade de los siglos XIII y XIV. Al citar esta flora en sus paredes, los arquitectos, poetas y artistas de la Alhambra incluyen anillos y pequeños círculos, tallos y pequeñas hojas que se superponen a la forma de una luna creciente, así como hojas de distinta y, en ocasiones, exagerada curvatura, con algunos granos de pimienta, o palmetas lobuladas y, otras veces, piñas y hojas sencillas o dobles de palmeras apuntando hacia arriba o hacia abajo. Esta fantasía casi musical de diseño muestra que los arquitectos de los palacios nazaríes de la Alhambra establecieron, en una forma tipo paródica, su propio estilo de integración del paisaje con la arquitectura, con lo cual representaron los jardines islámicos en sus yeserías que establecían una clara resonancia con los jardines de fuera de sus paredes. Con esto, los jardines dentro y fuera de la Alhambra representan una naturaleza que trasciende tiempo y espacio, y que en virtud de dicha transformación debida al agua y sus estados físicos, así como a los cambios en el paisaje, instalan en los palacios no solo unos signos léxicos de representación, sino una galería sinfónica de unidades simbólicas e icónicas que movilizan nuevos universos de significados asociados con el medio ambiente, con jerarquías socioculturales y con sentidos espirituales. Como el agua que circula por los canales y acequias de los palacios, así se conectan los jardines adentro y afuera, desde los ríos y la tierra hasta el yeso de las paredes (Imagen 3). En

Imagen 3. Mirador de Lindaraxa, Patio de los Leones. La Alhambra, Granada

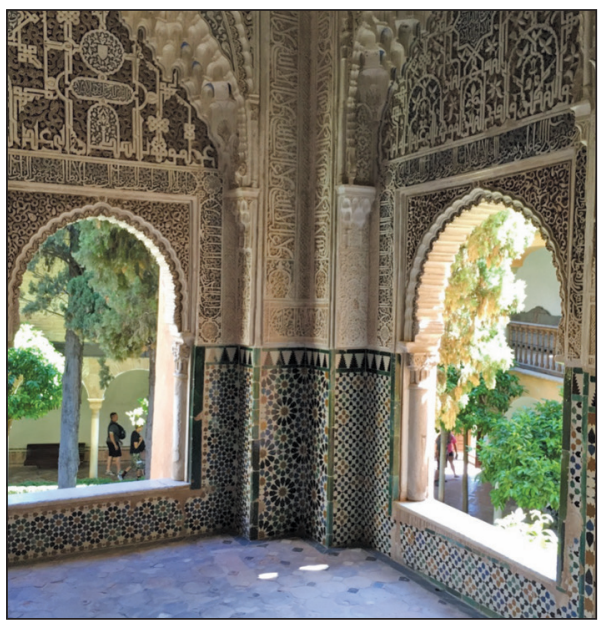

Fotografía: María M. Carrión. 
la Alhambra, pues, la arquitectura no solo representa o imita a la naturaleza, sino que, de hecho, la abarca, la engloba, la contiene y es contenida por ella.

Las flores que brotan entre los juegos geométricos y las inscripciones cúficas y cursivas de las yeserías transportan a los espectadores a otros lugares del orbe terráqueo. Así, por ejemplo, la flor de loto, cuya incorporación responde al deseo del sultán MuHammad $\mathrm{V}$ de que se representara su vívido interés y conocimiento de los desarrollos culturales del Mediterráneo, sobre todo los que se produjeron gracias al substancioso comercio que floreció en el Mediterráneo con los mamelucos. Esta flor, que como bien nota Mariam Rosser-Owen, se encuentra en los artesonados de madera del Palacio de los Leones, y sobre todo en las cuatro galerías que enmarcan el patio, es motivo artístico importado de la China al repertorio de diseño arquitectónico y artístico andalusí y nazarí como resultado de las conquistas mongoles de Irán e Iraq en la segunda mitad del siglo XIII, las cuales se transfirieron durante el XIV a Egipto y a Siria por medio de los productos de lujo que traficaron los mamelucos. En la Alhambra se cristalizaron en forma de jardines al revés, como los que Puerta Vílchez lee en estos poemas.

\section{Agua, medio del flujo de la fe y el amor}

No hay jardines monumentales ni una gran proliferación de elementos naturales en el Castillo interior. En el tramo ancla del tratado, como si de un aditamento se tratara, aparece una mención relacionada con la estructura divisoria del castillo: "Aunque no se trata de más de siete moradas, en cada una de éstas hay muchas: en lo bajo y alto y a los lados, con lindos jardines y fuentes y laberintos y cosas tan deleitosas, que desearéis deshaceros en alabanzas del gran Dios, que lo crio a su imagen y semejanza". ${ }^{25}$ La palabra árbol aparece tres veces -una en referencia a Dios, el árbol de la vida, una en significado opuesto, "que es el demonio" y la tercera, como signo del alma que, si vecina a las aguas de Dios, no sentirá penitencia. $-{ }^{26}$ Las flores se mencionan una sola vez y como mero instrumento para nombrar a las abejas. ${ }^{27}$ En el pasaje harto citado de la crianza de la seda y el gusano, las hojas de moral son nido de la simiente..$^{28} \mathrm{El} \mathrm{Castillo,} \mathrm{en} \mathrm{suma,} \mathrm{se}$ aleja de una sinfonía jardinera como la que encuentra el lector de la Alhambra, y se concentra, en su lugar, en el elemento indispensable de todo jardín: el agua. La genealogía del tratado nos ayuda a entender esta ausencia notoria de jardines, emblema de una presencia fantasmática de estos espacios.

25 Epílogo, 3.

26 M1 C1 N2; M1 C2 N4; y M7 C2 N9.

27 M1 C2 N9.

28 M5 C2 N2. 
Teresa de Jesús escribe este penúltimo libro por orden de su confesor, hábito que ya la había llevado a producir otros dos libros anteriores. Uno de ellos, el gran libro de los jardines, con veinte capítulos dedicados a la oración y a una amplia gama de jardines diversos, es el Libro de la vida. ${ }^{29} \mathrm{La}$ orden de escribir el Castillo surge como estrategia para contrarrestar la sospecha y persecución que había sufrido de Jesús a manos de la Inquisición al recibir manuscrito de la Vida y sus posibles sugerencias herejes. La ausencia de jardines puede interpretarse como una sublimación del libro anterior, otra huida del jardín agustiniano inscrito en la Vida con una copiosa exégesis del Jardín del Génesis.

Así pues, bajo la mirada inquisitiva del confesor y del Santo Oficio, una invitación a moverse libremente por diferentes jardines podría haberse leído como anatema. De hecho, la compleja y paradójica arquitectura del castillo sirve de salvaguarda para el sujeto que escribe, pues la pone a la orden de sus "superiores," quienes navegan las líneas divisorias de las distintas áreas de dicha fortificación. Los castillos, como indica su etimología (L. castellum, fuerte), fueron diseñados en principio para servir funciones de

29 En mi ensayo "Primero huerto" analizo en detalle la idea del jardín como signo místico en el Libro de la vida. defensa y guerra. ${ }^{30}$ En España, como en otros lugares de Europa, estos espacios se convirtieron en los espacios domésticos desde donde una poderosa nobleza rigió civilizaciones rigurosamente jerarquizadas, y donde las vidas y el movimiento de los seres humanos vinieron a ser significativamente regulados para satisfacer sus necesidades de vida, seguridad y esparcimiento. ${ }^{31}$ La idea de que cualquier individuo podía entrar en un castillo cuando y como quisiera, y moverse en sus predios libremente sin atenerse a la autoridad que regía dichos espacios contradice el grano arquitectónico de estas edificaciones. Lo que es aún más, para 1577 cuando de Jesús compone el

30 En una lectura limitada de la imagen arquitectónica del castillo, algunos críticos han interpretado el Castillo interior en relación con ciertas edificaciones históricas castellanas asociadas con el pasado exclusivamente cristiano de España. Así, por ejemplo, Miguel de Unamuno y Robert Ricart leen una inscripción de la muralla de Ávila en el tratado místico, mientras que Trueman Dicken nota la presencia del Castillo de La Mota en Medina del Campo en sus páginas. Aunque estas estructuras se corresponden con un nivel simbólico de las primeras moradas del Castillo, no ayudan a entender los aspectos que caracterizan los niveles teológicos más avanzados del texto de Tereza de Jesús.

31 Los estudios de Luis Monreal y Tejada y Edward Cooper ofrecen una introducción a este tema. La galería de semblanzas de ciertos miembros de la Casa de Trastámara hecha por Fernán Pérez de Guzmán revela algunos de los asuntos de movimiento y acceso en estos espacios durante la segunda mitad del siglo catorce. José Antonio Maravall, por su parte, conecta las jerarquías medievales en la sociedad castellana con lo que vino a ser una sociedad estamental al entrar en la modernidad en el siglo dieciséis. 
Castillo interior, el entrar en un espacio así "sin licencia de las superioras" (Epílogo, 1) representaba un desafío al decreto de 1564, según el cual todo súbdito de la corona debía obedecer a los representantes de la Iglesia y obedecer las reglas estipuladas en el Concilio de Trento. ${ }^{32}$ ¿Quiénes son, pues, estas "superioras" de quienes habla de Jesús? En el contexto inmediato en el que se movía de Jesús, el identificar las "superioras" como representantes de la Iglesia-Estado no sería un disparate; aún así, los representantes de la ortodoxia católica figurados en el Castillo no eran literalmente inquisidores, y no ejercían control total sobre el texto. De ahí que tenga sentido que su voz narradora les diga a sus hermanas que "os será consuelo deleitaros en este castillo interior, pues sin licencia de las superioras podéis entrar y pasearos por él a cualquier hora". ${ }^{33}$ Este nivel irónico permite a los lectores entender que, en su dimensión teológica, el Castillo interior no es literalmente una fortificación, sino un espacio en el que pueden deleitarse, porque es su propia alma. La imago castelar es, sin duda alguna, fachada de alianza con la Contrarreforma,

32 La Sesión XXV del Concilio de Trento, celebrada el 3 y 4 de diciembre de 1563 , estipulaba las nuevas reglas monásticas, las cuales incluían numerosos detalles sobre reliquias, imágenes sacras, monjes, monjas, y reformas monásticas (327-396).

33 Epílogo, 1; énfasis mío. sus tradiciones y su fe. ${ }^{34}$ Ahora bien, interpretar estos muros literalmente y cerrar la reflexión teológica en un fervor contrarreformista es reducir el Castillo a un tratado de guerra religiosa y defensa de una versión particular del Catolicismo, lo cual coloca tanto el libro como a su autora en un punto de estasis que le niega la capacidad de moverse, traducir, trasladarse, y de significar de modo alternativo. El símil establecido por la voz narradora -que el castillo interior es el alma del lector- es un buen punto de partida para desarticular esta lectura unívoca; ahora bien, esta interpretación parece faltarle al respeto a la autoridad absoluta de los dogmas y políticas contrarreformistas. ${ }^{35}$ Como tantos otros textos artísticos de este período de la historia cultural de España, en principio este espacio es un laberinto referencial que invita a sus lectores a

34 Alison Weber caracteriza el Castillo como un libro con un uso de una "retórica de la ofuscación,” en la cual las imágenes bélicas de las primeras tres Moradas y el uso de la imagen del miles Christi sirven como una alegoría de la vida monástica medieval, para representar "al alma cristiana concebida como un soldado que debe luchar activamente contra el mal desde dentro, y la tentación desde fuera" (110).

35 En 1564 el Rey Felipe II firmó una cédula real en la que ordenaba que todos los prelados y representantes de la Iglesia-Estado, y en particular a los "guardianes de las órdenes," que publicaran, guardaran y cumplieran, y que hicieran guardar y cumplir y ejecutar estas leyes "con el cuidado, zelo y diligencia que negocio tan de servicio de Dios, y bien de su iglesia requiere" (2). A esta cédula le siguieron los documentos del nuevo programa conciliar en España: el Catecismo Romano, el Índice de Libros Prohibidos y el nuevo Manual de la Misa, entre otros. 
jugar en un contexto cuidadosamente estructurado y controlado, reflejo del espacio religioso que ordenaba la corona Contrarreformista. ${ }^{36} \mathrm{~A}$ ello, çde Jesús le añade signos de conflicto y ambigüedad con los que edifica una estructura que difiere de las fortificaciones pétreas erigidas para servir funciones de guerras santas y las nuevas noblezas urbanas de su contexto. El Castillo, diseñado más a imagen y semejanza de estructuras transculturales, como la Alhambra, representa un lugar Otro en el que sujetos exílicos se pueden mover sin colapsar sus memorias y subjetividades dentro de una celda de identidad estática, literalmente ajena al lugar que antaño conocieron como el hogar.

De Jesús inscribe estas tradiciones literarias y arquitectónicas no solo para articular un argumento crítico o polémico, sino para responder a un llamado de cohabitar con la diferencia. En un gesto que interroga las fronteras histórico-ideológicas que se han erigido a su alrededor, el Castillo teoriza los actos de construir y escribir como una

36 Los lectores que, por una parte, conocen el Castillo interior y, por otra, tienen conciencia del "paraíso desde la Tierra" que María Moreno Alcalde ve representado en el Techo de Comares y otras manifestaciones en la arquitectura hispanomusulmana podrían asociar de inmediato el palimpsesto de imágenes del tratado místico con la cúpula del palacio nazarí (61-63). Darío Cabanelas ha identificado la representación de siete cielos coránicos en este Techo, los cuales ve coronados por un octavo cielo donde se encuentra el trono de Allāh. aproximación a lo divino. En este sentido, el libro establece una conexión clara con lo que Cynthia Robinson ha llamado "ver el Paraíso," evento que formaba parte de los ritos de los maj lis (s. majlis) en las tradiciones corteses de las taifas andalusíes, donde "la literatura y el palacio se codificaban por igual, y se referían entre sí, mutuamente; para entrar al paraíso, uno primero tiene que percibirlo". ${ }^{37}$ En las anécdotas de los rituales de estas soirées reales, las cuales Robinson cuenta como elementos claves para dichos eventos, la composición y estructura de la poesía constituían claves de lectura que, como se verá, se pueden aplicar también a la lectura del Castillo interior: "En esta estructura, la introducción y la conclusión encierra (es decir, protege y esconde) la selección poética, cuyas metáforas tendrán un significado verdadero (es decir, místico o no-sun$n$ ) impenetrable para todo aquel que no ha sido iniciado". ${ }^{38}$ De Jesús representa sus edificios para que los lectores imaginen e interpreten, y a una misma vez entabla la necesidad de entender este evento espiritual y literario:

Es menester que vayáis advertidas a esta comparación. Quizá será Dios servido pueda por ella daros algo a entender de las mercedes que es Dios servido hacer a las almas y las

37 Cynthia Robinson, "Seeing Paradise: Metaphor and Vision in taifa Palace Architecture" Gesta 36 (1997) 2: 145 .

38 Ibíd., 152. 
diferencias que hay en ellas, hasta donde yo hubiere entendido que es posible; que todas será imposible entenderlas nadie, según son muchas, cuánto más quien es tan ruin como yo. ${ }^{39}$

Como bien plantea Robinson, el elemento material de los arcos entrelazados y las inscripciones en los muros de la Aljafería de Zaragoza hacen posible que las actividades rituales de los maj lis se conviertan en plataformas para alcanzar el nivel de éxtasis necesario para unirse a la entidad significativa de dicho ritual, para entender la divinidad. Las inscripciones en estos muros sugieren, como las paredes letradas del Castillo, que en el proceso de ver, experimentar y aprehender las contradicciones allí escritas, los lectores pueden fundirse en unión mística con el referente, acceder a la cámara central del majalis, y así alcanzar la luz que emana de ese lugar del Otro. ${ }^{40}$

39 M1 C1 N3.

40 La luz desempeña un papel principal en el diseño de espacios andalusíes. Juan Carlos Ruiz Souza analiza cómo funciona este elemento arquitectónico en la constitución estética de la Mezquita de Córdoba, donde la luz se empleó para monumentalizar la fachada de Al-Ḥakam II, así como en la cúpula de Mocárabes en la Alhambra, donde Ruiz Souza propone que la célula arquitectónica del mocárabe y su constante juego con la luz diurna se usó para darle un cuerpo material a la teoría de la atomicidad de Abū Bakr MuHammad al-Bāqillānī (muerto en el año 1013), la cual postulaba que el color, la forma y el tamaño, así como otros elementos corporales, son efímeros y transitorios.
La belleza de este lugar en Zaragoza, considerado monumento de las tradiciones arquitectónicas taifas en al-Andalus, no depende de los tipos de materiales empleados en su diseño y construcción, ni de unas reglas externas de proporciones y ornamento, ni de una relación literal entre los diferentes niveles de estructura y articulación del espacio y la experiencia que ahí se puede dar. De Jesús traduce esta premisa estética y espiritual con su uso de unidades ajardinadas, las cuales quedan escondidas entre las paredes del castillo: así, los árboles, las hojas, las flores, la tierra y el agua. Sobre todo, el agua. En el Castillo cada instancia narrativa parece ser y estar dislocada de las otras, tal y como las estancias de los qu r nazaríes de la Alhambra parecen desentenderse de los muchos espacios palaciegos y de las bóvedas efímeras: "un castillo todo de un diamante o muy claro cristal, adonde hay muchos aposentos, así como en el cielo hay muchas moradas". ${ }^{41}$ No obstante esta complejidad, hay un principio que organiza los espacios y hace que la circulación por dichos aposentos caiga en su sitio, con lo cual el cuerpo antaño encerrado halla su punto de liberación en el Castillo: "Duélenos todo el cuerpo; mas si la cabeza está sana, no porque duele el cuerpo, dolerá la cabeza". ${ }^{2}$

41 M1 C1 N1.

42 M7 C2 N11. 
No hay una entidad original para esta instancia mimética particular, y de ahí que no haya "para qué nos cansar en querer comprender la hermosura de este castillo". ${ }^{43}$ El texto del Castillo invita a sus lectores a entrar a un lugar de conciencia suprema, donde "no es pequeña lástima y confusión que, por nuestra culpa, no entendamos a nosotros mismos ni sepamos quién somos". ${ }^{44} \mathrm{Al}$ circular por esta fortificación arquitectónica y literaria que hace hincapié en las contradicciones inherentes de aprehender y entender la divinidad, y de construir un espacio significativo por ello, los lectores pueden desarrollar un entendimiento diferente de la poesía, sus cuerpos y su medio ambiente, y con ello posiblemente hacerse de una anatomía crítica de estos textos y lo que representan: "Antes que pase adelante, os quiero decir que consideréis qué será ver este castillo tan resplandeciente y hermoso, esta perla oriental, este árbol de vida que está plantado en las mismas aguas vivas de la vida, que es Dios, cuando cae en un pecado mortal". ${ }^{45}$

El agua es elemento de base para la producción fantasmática del jardín en el Castillo interior. Tras ese manantial de las aguas vivas de la vida, el agua que comparece es la contraria, la que inunda el alma pecadora que se aparta de aquella Fuente "y se planta en otra de muy

43 M1 C1 N1.

$44 \mathrm{M} 1 \mathrm{C} 1 \mathrm{~N} 2$.

$45 \mathrm{M} 1 \mathrm{C} 2 \mathrm{~N} 1$.
Imagen 4. Palacio de Comares y su reflejo en el estanque del

Patio de los Arrayanes

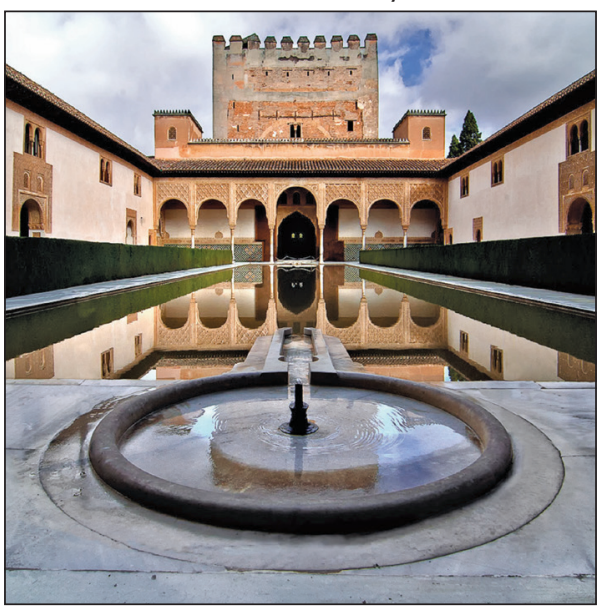

La Alhambra, Granada.

Fotografía: María M. Carrión.

negrísima agua y de muy mal olor," que no trae sino desventura y suciedad. ${ }^{46} \mathrm{De}$ ahí el agua pasa a ser camino; o como elemento que "se despeña," con lo que le añade al ruido que aqueja la cabeza de la autora. ${ }^{47}$ En el mezzo della sua vita el lector se topa con un núcleo referencial clave en el que habla sobre los 'gustos de Dios' u 'oración de quietud,' los cuales explica por medio del agua en una imagen que bien podría estar dialogando con el reflejo del estanque del Patio de los Arrayanes en el Palacio de Comares (Imagen 4):

Hagamos cuenta, para entenderlo mejor, que vemos dos fuentes con dos pilas que se hinchen de agua,

$46 \quad \mathrm{M} 1 \mathrm{C} 2 \mathrm{~N} 2$.

47 M3 C2 N7; M4 C1 N10. 
que no me hallo cosa más a propósito para declarer algunas de espíritu que esto de agua; y es, como sé poco y el ingenio no ayuda y soy tan amiga de este elemento, que le he mirado con más advertencia que otras cosas. ${ }^{48}$

La exégesis de estos gustos divinos, del placer de la oración de quietud tan sospechosa durante la Contrarreforma amerita un segundo versículo:

Estos dos pilones se hinchen de agua de diferentes maneras: el uno viene de más lejos por muchos arcaduces y artificio; el otro está hecho en el mismo nacimiento del agua y vase hinchendo sin ningún ruido, y si es el manantial caudaloso, como éste de que hablamos, después de henchido este pilón procede un gran arroyo; ni es menester artificio, ni se acaba el edificio de los arcaduces, sino siempre está procediendo agua de allí. ${ }^{49}$

La diferencia entre unos y otros, concluye de Jesús, radica en que los 'contentos' de la meditación es el agua traída por arcaduces, espejo de ese manantial principal, que es el agua enviada por Dios.

En memoria casi literal de los cuatro modos de irrigación del jardín-alma de la Vida, donde la forma arquitectónica representaba casas y conventos, la inscripción del flujo se traduce a la arquitectura del castillo:

$48 \mathrm{M} 4 \mathrm{C} 2 \mathrm{~N} 2$

$49 \mathrm{M} 4 \mathrm{C} 2 \mathrm{~N} 3$.
Estotra fuente, viene el agua de su mismo nacimiento, que es Dios, y así como Su Majestad quiere, cuando es servido hacer alguna merced sobrenatural, produce con grandísima paz y quietud y suavidad de lo muy interior de nosotros mismos, yo no sé hacia dónde ni cómo, ni aquel contento y deleite se siente como los de acá en el corazón -digo en su principio, que después todo lo hinche-, vase revertiendo este agua por todas las moradas y potencias hasta llegar al cuerpo; que por eso dije que comienza de Dios y acaba en nosotros; que cierto, como verá quien lo hubiere probado, todo el hombre exterior goza de este gusto y suavidad..$^{50}$

Este agua que llega al cuerpo es del corazón, "de otra parte aun más interior, como una cosa profunda," el centro del alma. ${ }^{51}$ En otro eco de la Vida, la voz narradora diferencia el agua traída por arcaduces de la que Dios concede, la cual "aunque más meditación tengamos y aunque más nos estrujemos y tengamos lágrimas" solo llegará si Él quiere y el alma no la busca. ${ }^{52}$

A medida que avanza el texto, el agua se hace tan poderosa que puede hinchar o dilatar el cuerpo, y hasta ensanchar un edificio. ${ }^{53}$ Ese pilar de agua se ve desatado en las Sextas Moradas, donde "con un ímpetu grande se

50 M4 C2 N4.

51 M4 C2 N5.

52 M4 C2 N9.

53 M4 C3 N9. 
levanta una ola tan poderosa, que sube a lo alto de esta navecica de nuestra alma". ${ }^{54}$ Ante el poder divino, las lágrimas pueden ser riego y llevar a la humildad, ante la cual Él puede darnos "lo que quisiere, siquiera haya agua, siquiera sequedad: Él sabe mejor lo que nos conviene" ${ }^{55}$ El último flujo del agua en esta penúltima etapa del tratado reitera la imperfección, la insuficiencia, y la sed como emblemas del anhelo de unión: "Cuánto más que, si es purificar esta alma para que entre en la séptima morada, como los que han de entrar en el cielo se limpian en el purgatorio, es tan poco este padecer, como sería una gota de agua en la mar". ${ }^{56}$

Así como el agua habla con elocuencia sobre el deseo y el anhelo de la unión, así se expresa sobre la diferencia que caracteriza el desposorio espiritual: "Acá es como si cayendo agua del cielo en un río o Fuente, adonde queda hecho todo agua, que no podrán ya dividir ni apartar cual es el agua, del río, o lo que cayó del cielo; o como si un arroyico pequeño entra en la mar, no habrá remedio de apartarse" ${ }^{57} \mathrm{El}$ gozo que se experimenta en esta unión resuena con tres golpes de agua, "como sentiría este agua una persona que está descuidada si la bañasen de presto en ello, y no lo podía dejar de sentir" ${ }^{58} \mathrm{El}$

54 M6 C5 N3.

55 M6 C6 N9.

56 M6 C11 N6.

57 M7 C2 N4.

58 M7 C2 N6. árbol junto a las aguas no es irrevocable, pues llegar a este estado de unión no significa que la salvación esté segura, ni que no se pueda volver a caer en pecado. Solo el agua celestial puede mantener el árbol fresco y con fruto..$^{59}$ Con el agua cierra de Jesús el viaje espiritual del castillo interior:

Aquí se dan las aguas a esta cierva, que va herida, en abundancia. Aquí se deleita en el tabernáculo de Dios. Aquí halla la paloma que envió Noé a ver si era acabada la tempestad, la oliva, por señal que ha hallado tierra firme dentro en las aguas y tempestades de este mundo. ¡Oh Jesús! Y ¡quién supiera las muchas cosas de la Escritura que debe haber para dar a entender esta paz del alma! ${ }^{60}$

La virtuosa tipología escrituraria de este último tramo de agua incorpora ecos de poesía mediterránea y tipología bíblica. Cerrar el castillo a una lectura exclusivamente católica es ignorar lo que para Clooney es la perspectiva más importante de una teología comparada, a saber, "la lectura de textos, preferiblemente sagrados y teológicos que han sobrevivido siglos y milenios, y que han guiado a comunidades en su comprensión de Dios, de su ser y del ser del otro". ${ }^{61}$ Porque es precisamente en el acto de lectura donde se forja el aprendizaje religioso;

59 M7 C2 N9.

60 M7 C3 N13.

61 Clooney, Comparative Theology, 58. 
porque no se trata de meros actos de recitación y reiteración, sino de interpretación y sensación, de emprender, como dice Clooney, "ciertos actos de lectura, cuando leemos para atrás y para adelante, cruzando fronteras religiosas, examinando múltiples textos, individualmente, pero así también el uno a la luz del otro". ${ }^{6}$

Al final del juego, la Alhambra y de Jesús apuestan al agua y a los jardines, y descartan los gruesos pilares de la tierra que caracterizaron las estructuras catedrales como únicos lugares sagrados de las reglas de práctica de la fe católica. En sus textos literarios y conventos Carmelitas reformados, de Jesús ejerce una voluntad tangible de separar su "teulogía" de los llamados del dogma católico prescrito, y en su lugar favorece métodos de diseño espacial y arquitectónico que comparten lugares, métodos y tradiciones andalusíes como se ven en la Alhambra. A pesar de que la propia Madre Carmelita identifica su vida y obra con la fe católica, sus escritos y su reforma conventual participan en espacios y rituales considerados herejes al resistir la práctica de una sola teología. Su Castillo interior, espacio de una teología comparada tangible con los espacios palaciales de la Alhambra, representa una serie de espacios letrados y monásticos que constituyen un nexo fundamental con los atauriques y el agua como signos de arquitectura islámica en los palacios nazaríes y sus jardines. Con ello, de Jesús hermana su teología con la de los laberintos de austeridad y sinfonía escrituraria, geométrica y artística de la Alhambra. Con este tapiz de lacerías arquitectónicas y textuales hilvanadas por el agua, la Alhambra y el Castillo Interior avanzan nuevos significados en una memoria histórica que desde 1492 se destinó al olvido. Se puede optar por la mirada turística pasajera y dejar así a la Alhambra y al Castillo interior, no muy lejos de donde la han dejado algunos notorios lectores: por ejemplo, como objeto del oscuro deseo romántico de Washington Irving, cuyo 'cuarto' se conserva con detalles arquitectónicos renacentistas; o como el bastión de una nostalgia imperial en la filosofía de Unamuno. En suma, podemos dejar estos dos textos en lugares pintorescos, dignos de retratos de portada de libro, donde no hay mucho más que decir. Pero también podemos darles la vuelta a estas lecturas, y leer estos jardines y sus aguas, en su dimensión de profunda lectura teológica comparada. 


\section{Bibliografía}

Anderson, Benedict. Imagined Communities. Reflections on the Origin and Spread of Nationalism. New York: Verso, 2006.

Bhabha, Homi. "Cultural Diversity and Cultural Differences." The Post-Colonial Studies Reader. B. Ashcroft, G. Griffiths y H. Tiffin (eds). New York: Routledge, 2006. 206-209.

Cabanelas, Darío. El techo del Salón de Comares en La Alhambra. Decoración, policromía, simbolismo y etimología. Granada: Patronato de La Alhambra, 1988.

Carrión, María M. “Amor a Dios, por amor al arte. Arquitectura e iconografía en la narrativa de Teresa de Jesús." Repensando la experiencia mística desde las ínsulas extrañas. Ed. Luce López-Baralt y Beatriz Cruz Sotomayor. Madrid: Trotta, 2013. 277-308.

"Primero huerto. Iconography, Anamorphism, and the Idea of the Garden in Sixteenth-Century Spanish Mysticism." La Corónica 41 (2012) 1: 61-92.

-. "Scent of a Mystic Woman. Teresa de Jesús and the Interior Castle." Medieval Encounters 15 (2009): 130-156.

Clooney, Francis. Comparative Theology: Deep Learning Across Religious Borders. Chichester, West Sussex: Wiley-Blackwell, 2010.
Cooper, Edward. Castillos señoriales en la corona de Castilla. 4 vols. Madrid: Junta de Castilla y León, 1991.

De Jesús, Teresa. Obras completas. Efrén de la Madre de Dios y Otger Steggink, eds. Madrid: Biblioteca de Autores Cristianos, 1986.

González Alcantud, José Antonio (dir.), Sandra Rojo Flores y José Muñoz. La Alhambra, mito $y$ vida. 1930-1990. Tientos de memoria oral y antropología de un Patrimonio de la Humanidad. Granada: Universidad de Granada, 2016.

Dicken, Trueman. "The Imagery of the Interior Castle and its Implications." Ephemerides Carmeliticae XXI (1970): 198-218.

López-Baralt, Luce. Asedios a lo indecible. San Juan de la Cruz canta al éxtasis transformante. Madrid: Trotta, 1998.

- San Juan de la Cruz y el Islam. Madrid: Hiperión, 1990.

—. "Simbología mística musulmana en San Juan de la Cruz y en Santa Teresa de Jesús." Nueva Revista de Filología Hispánica 30 (1981) 1: 21-91.

López de Ayala, Ignacio. El sacrosanto y ecuménico Concilio de Trento, traducido al idioma castellano. Barcelona: Imprenta de D. Ramón Martín Indár, 1847. 
MacDonald, Mary (ed). Experiences of Place. Cambridge, Massachussets: Harvard University Press, 2003.

Maravall, José Antonio. "La sociedad estamental castellana y Don Juan Manuel." Estudios de historia del pensamiento español. Edad Media. Madrid: Ediciones Cultura Hispánica, 1983.

- Estado moderno y mentalidad social (siglos XV a XVII). 2 vols. Madrid: Revista de Occidente, 1972.

Monreal y Tejada, Luis. Medieval Castles of Spain. Cologne: Könemann, 1999.

Moreno Alcalde, María. "El paraíso desde la tierra. Manifestaciones en la arquitectura hispanomusulmana." Anales de Historia del Arte 15 (2005): 51-86.

Pérez de Guzmán, Fernán. Generaciones y semblanzas. Ed. José Antonio Barrio. Madrid: Cátedra, 1998.

Puerta Vílchez, José Miguel (ed). Leer La Alhambra. Guía visual del monumento a través de sus inscripciones. Granada: Edilux. Patronato de La Alhambra y Generalife, 2011.

Robert Ricart. "Le symbolisme du 'Château intérieur' chez Sainte Thérèse." Bulletin Hispanique LXVII (1965): 27-41.
Robinson, Cynthia. "Seeing Paradise: Metaphor and Vision in taifa Palace Architecture" Gesta 36 (1997) 2: 145-155.

-. "The Aljafería in Saragossa and Taifa Spaces." En Literature of Al-Andalus. María Rosa Menocal, Raymond P. Scheindlin y Michael Sells (eds). Cambridge: Cambridge University Press, 2006. 233-234.

Ruggles, D. Fairchild. "Ideologizing the Past." International Journal of Middle Eastern Studies 45 (2013): 574-577.

-. "The Eye of Sovereignty: Poetry and Vision in the Alhambra's Lindaraja Mirador," Gesta 36 (1997) 2: 180-189.

Ruiz Souza, Juan Carlos. "La fachada luminosa de Al-Hakm II en la Mezquita de Córdoba. Hipótesis para el debate (Tafel 4143)." Sonderdruck aus Madrider Mitteilungen 42 (2002): 432-445

$$
\text { "El Palacio de los Leones }
$$
en La Alhambra: ¿Madrasa, Zawiya y Tumba de Muhammad V? Estudio para un debate." AlQantara XXII (2001) 1: 77-120.

- "La cúpula de Mocárabes y el Palacio de los Leones de la Alhambra." Anuario del Departamento de Historia y Teoría del Arte (UAM) Vol. XII (2000): 9-24. 
Swietlicki, Catherine. "The Proble- Weber, Alison. Teresa of Avila and the matic Iconography of Teresa of Avila's Interior Castle." Studia Mystica 11 (1988): 37-47. Rhetoric of Femininity. Princeton: Princeton University Press, 1990.

Tejada y Ramiro, D. Juan (trad). Colección de canones y de todos los concilios de la Iglesia española. Concilios del Siglo XV en adelante. Vol. 4. Madrid: Imprenta de D. Pedro Monterio, 1853. 
